\title{
High-dose steroids for the treatment of severe COVID-19: a new therapeutic tool?
}

\author{
Paolo Cameli $^{1}$ - Laura Bergantini ${ }^{1}$ - Miriana d'Alessandro ${ }^{1}$ Elena Bargagli ${ }^{1} \mathbb{C}$
}

Received: 16 March 2021 / Accepted: 22 March 2021 / Published online: 19 April 2021

(c) Società Italiana di Medicina Interna (SIMI) 2021

Keywords COVID-19 $\cdot$ Treatment $\cdot$ Steroids

The interesting Research Letter by Piccica et al. focuses on a hot topic of the last 2 years, since the SARS-CoV-2 pandemic caused an unprecedented crisis of national health systems all over the world. Few therapeutic approaches have so far been approved for the management of COVID-19 and only steroids have been demonstrated to reduce mortality in patients with acute respiratory failure [2]. This evidence comes from the large multicentre RECOVERY trial, in which intravenous dexamethasone $(6 \mathrm{mg}$ once daily for up to 10 days) caused a significant reduction in the incidence of death. These findings, in combination with the substantial lack of efficacy of antivirals and immunomodulatory drugs [3-5], has led to a change in paradigm in the clinical management of COVID-19, dexamethasone marking a milestone in pharmacological treatment.

However, some uncertain aspects still remain. First, since the rationale of dexamethasone in COVID-19 is to modulate and mitigate inflammation-mediated lung injury, a weightbased dosing of steroid therapy could be more appropriate. Second, most patients hospitalized for COVID-19 with need for oxygen therapy and/or respiratory support take more than 10 days to recover [6]: it seems reasonable that dexamethasone could be given for more than 10 days, but no solid supporting evidence is yet available. Third, a significant proportion of patients who recover from COVID-19 complain of persistent respiratory symptoms associated with parenchymal fibrotic strands and persisting CT evidence of groundglass opacities, even 3 or 6 months after hospital discharge $[7,8]$ : a higher dose of steroid therapy may help tackle the

Elena Bargagli

bargagli2@gmail.com

1 Department of Medical Sciences, Surgery and Neurosciences, Respiratory Diseases Unit, Siena

University, 53100 Siena, Italy inflammatory burden in an early phase of disease, hopefully lowering the probability of developing chronic lung damage.

Piccica et al. described their experience with a high dose of intravenous methylprednisolone ( $\geq 2 \mathrm{mg} / \mathrm{kg} /$ day $)$ in a small cohort of hospitalized COVID-19 patients [1]. All patients showed radiography and/or high resolution computed tomography evidence of lung infiltration and needed respiratory support with oxygen and/or mechanical ventilation. Despite significant deterioration in clinical status at baseline (in terms of $\mathrm{PaO} 2 / \mathrm{FiO} 2$ ratio and prevalence of ARDS) in the high-dose group, the authors did not observe a statistically significant difference in mortality between the low- and high-dose steroid cohort. Significantly, the latter group showed a longer latency of therapy from onset of symptoms, suggesting that a higher dose of methylprednisolone may also be helpful in advanced COVID-19 pneumonia. Finally, no evidence of severe or unexpected adverse events was reported.

The results of Piccica et al. [1] are intriguing as they suggest that a higher dose of steroids may be beneficial in terms of early mortality, especially in patients with advanced disease and/or "do not resuscitate" status, for whom it could be a potential therapeutic option.

High-dose intravenous steroids are a promising tool for the management of severe cases of COVID-19 also by virtue of wide drug availability in all care settings and its well-known safety profile. However, more and larger studies are needed to better understand the effectiveness of this approach compared with fixed-dose dexamethasone, currently the gold standard treatment for this severe condition. 
Funding None.

\section{Declarations}

Conflict of interest The authors declare that they have no conflict of interest.

Statement of human and animal rights This comment does not contain any studies with human or animal participants performed by any of the authors.

Informed consent For this type of study, formal consent is not required.

\section{References}

1. Piccica M, Lagi F, Trotta M, Spinicci M, Zammarchi L, Bartoloni A, for the COCORA working group. High-dose steroids for the treatment of severe COVID-19. https://doi.org/10.1007/ s11739-021-02707-x

2. RECOVERY Collaborative Group, Horby P, Lim WS, Emberson JR, Mafham M, Bell JL et al (2021) Dexamethasone in hospitalized patients with COVID-19. N Engl J Med 384(8):693-704
3. Lora-Tamayo J, Maestro G, Lalueza A, Rubio-Rivas M, Villarreal Paul G, Arnalich Fernández F et al (2021) Early Lopinavir/ ritonavir does not reduce mortality in COVID-19 patients: Results of a large multicenter study. J Infect. https://doi.org/10.1016/j.jinf. 2021.02.011

4. RECOVERY Collaborative Group, Horby P, Mafham M, Linsell L, Bell JL, Staplin N et al (2020) Effect of hydroxychloroquine in hospitalized patients with COVID-19. N Engl J Med 383(21):2030-2040

5. Beigel JH, Tomashek KM, Dodd LE, Mehta AK, Zingman BS, Kalil AC et al (2020) Remdesivir for the treatment of COVID19-final report. N Engl J Med 383(19):1813-1826

6. Huang C, Wang Y, Li X, Ren L, Zhao J, Hu Y et al (2020) Clinical features of patients infected with 2019 novel coronavirus in Wuhan, China. Lancet Lond Engl 395(10223):497-506

7. Huang C, Huang L, Wang Y, Li X, Ren L, Gu X et al (2021) 6-month consequences of COVID-19 in patients discharged from hospital: a cohort study. Lancet Lond Engl 397(10270):220-232

8. Wu Q, Zhong L, Li H, Guo J, Li Y, Hou X et al (2021) A followup study of lung function and chest computed tomography at 6 months after discharge in patients with coronavirus disease 2019. Can Respir J 2021:6692409

Publisher's Note Springer Nature remains neutral with regard to jurisdictional claims in published maps and institutional affiliations. 